\title{
Dental treatment under general anesthesia in adults with special needs at the University Hospital of Dental Prosthetics and Restorative Dentistry of Innsbruck, Austria: a retrospective study of 12 years
}

\author{
Dagmar Schnabl $^{1}$ - Annachiara Guarda ${ }^{1}$ - Maria Guarda ${ }^{1} \cdot$ Lia Marie Irmtraut von Spreckelsen ${ }^{1} \cdot$ Marina Riedmann $^{2}$. \\ Rene Steiner $^{1} \cdot$ Herbert Dumfahrt $^{1}$
}

Received: 16 February 2018 / Accepted: 13 February 2019 / Published online: 4 March 2019

(C) The Author(s) 2019

\begin{abstract}
Objectives Special needs patients are prone to insufficient oral care and subsequent caries or periodontitis. The aim of this retrospective study was the assessment of demand for restorative therapy and tooth extractions under general anesthesia in adults with intellectual and/or physical disablement (IPD) or psychiatric disorders (PDs) with inherent dentist phobia at the University Hospital of Innsbruck with regard to demographic factors.

Materials and methods A total of 444 consecutive cases of scheduled dental general anesthesia (DGA) in adults from 2003 to 2014 were included. From patient files, demographic data, the presence of either IPD or a PD, attested by a mandatory certificate, and restorative therapy and tooth extractions performed under DGA were obtained. Data analysis was carried out by means of descriptive and comparative statistics.

Results Four hundred two cases (mean age $37.5 \pm 13.87$ years) assigned to 283 individuals with IPD and 42 cases (mean age $36.09 \pm 13.03$ years) assigned to 39 individuals with PDs arose in the observed period. Patients with PDs required significantly more restorations (in $7.98 \pm 5.4$ versus $5.34 \pm 4.41$ teeth; $p=0.002$; Mann-Whitney $U$ test) and extractions (of $4.86 \pm 4.51$ versus $2.6 \pm 3.96$ teeth; $p<0.001$; Mann-Whitney $U$ test) than patients with IPD.

Conclusions Demand for dental treatment was high in the collective of special needs patients. Oral health status was worse in patients with PDs than in patients suffering IPD.

Clinical relevance While in patients with severe disablement, DGA presents the only treatment option, specific preventive programs should be implemented for patients with minor disablement or dentist phobia. In these patients, alternative approaches should be promoted.
\end{abstract}

Keywords Dental general anesthesia $\cdot$ Special needs · Intellectual disablement $\cdot$ Physical disablement $\cdot$ Psychiatric disorders · Dentist phobia

\section{Introduction}

According to a recent review, currently there are no certain accepted protocols for the provision of dental treatment under general anesthesia (dental general anesthesia, DGA) to patients

Dagmar Schnabl

dagmar.schnabl@tirol-kliniken.at

1 University Hospital of Dental Prosthetics and Restorative Dentistry, Medical University of Innsbruck, 6020 Innsbruck, Austria

2 Department of Medical Statistics, Informatics and Health Economics, Medical University of Innsbruck, 6020 Innsbruck, Austria with special needs [1]. However, DGA presents the most commonly used technique for non-cooperative patients in need for (extensive) dental rehabilitation [2]. Dentistry for individuals with special needs (also referred to as persons with "disablement," comprising the levels "impairment," "disability," and "handicap," as defined by the WHO [3]) encompasses the management of patients with intellectual, physical, psychiatric, and complex medical problems [4]. Such patients are prone to insufficient oral care and subsequent caries or periodontitis [5-9] and frequently display anxiety and non-cooperation, rendering routine dental examination or treatment arduous or impossible. Several studies have assessed a high caries prevalence in children and adults with special needs worldwide with decayed-missing-filled teeth (DMFT) 
scores ranging from around 12 to more than 23 in dependence of age and other factors such as ability to cooperate with dental treatment and type of residence [6, 7, 9-11]. Patients with IPD frequently need assistance in daily oral care and depend on caretakers to arrange and keep dentist appointments. In patients who are unamenable to conventional dental procedures, DGA provides optimized treatment conditions. However, DGA requires high efforts in terms of personnel and financial expenditure within a hospital stay [12]. Moreover, multimorbidity and/or intellectual disability implicate an increased risk of anesthetic complications and a delayed recovery after the procedure [13-17]. Time spans from admission to DGA should be kept as short as possible within the hospital's means in order to hold down anxiety, progression of caries/ inflammatory processes, and pain during the wait [18].

Little literature is available on the state of oral health in special needs patients in Austria. A few studies relate to geriatric inhabitants of nursing homes. One study in around 680 home residents (mean age over 85 years) found a mean DMFT score of $25.6 \pm 4.2$ and shortcomings of oral care and prosthodontic rehabilitation [19]. Two investigations assessed the extent of denture hygiene (in relation to cognitive status) and denture retention in residents of retirement homes (mean age over 80 years) and also identified a need for improvement of oral care and denture maintenance/fitting [20, 21]. The individuals admitted to DGA at the Hospital of Innsbruck are considerably younger and usually suffer disablement not associated with age-related diseases. The aim of this study was the breakdown of diagnoses and the quantification of demand for restorative therapy and/or tooth extractions under scheduled DGA in adult persons with special needs in order to contribute relevant data to healthcare policies.

\section{Material and methods}

\section{Subjects}

All consecutive cases $(n=444)$ of scheduled DGA in adult patients (older than 16 years) at the University Hospital of Innsbruck from January 1, 2003, to December 31, 2014, served as study population. At admission for DGA, patients with IPD were usually attended by their caretakers. Obvious carious decay, broken or loose teeth, or presumed pain frequently presented reasons for seeking consultation. Depending on the patient's general and mental condition, a clinical examination was attempted by the consultant in charge. If possible, an orthopantomogram (OPG) was taken in order to assess the need for dental treatment. (In rare cases of non-amenability to a clinical assessment and imaging, explorative DGA including professional oral hygiene was indicated on speculation.) Patients with PDs with inherent anxiety or dentist phobia who were claiming DGA were only admitted upon presentation of a certificate by a consultant psychiatrist testifying the inability to undergo standard dental treatment under local anesthesia. The obligation to present such a certificate was introduced in January 2007. A preoperative internistic check-up with respect to suitability for general anesthesia was usually performed at the outpatient clinic of the Department of Anaesthesiology and Critical Care Medicine. With preoperative informed consent given by the patient or his/her legal guardian, DGA was accomplished in the course of a dayunit stay (or a prolonged hospitalization, if necessary for medical reasons) at the inpatient department of the University Hospital of Cranio-Maxillofacial and Oral Surgery. DGA included scaling and tooth polishing, a clinical assessment, intraoperative single tooth radiographs in case of absence of a preoperative OPG, restorative therapy of carious teeth by means of composite (Tetric EvoCeram, Ivoclar Vivadent, Schaan, Liechtenstein; bonding Optibond $^{\mathrm{FL}}$, Kerr, Biberach, Germany), and extraction of profoundly carious teeth presenting vital or avital pulp exposition on excavation. In order to keep duration of general anesthesia short and to ensure postoperative long-term absence of pain, endodontic treatment was not performed under DGA.

\section{Study design and data acquisition}

The study was designed as a retrospective analysis of anonymized demographic data, medical and dental findings, and dental therapy performed under general anesthesia, derived from digital patient files. Ethical approval to the study protocol was obtained by the institutional ethical committee, study number 2014-0269 341/4.8 (3621a).

The following anonymized data were extracted from patient files, coded by numbers, and tabularized (Excel, Microsoft, Redmont, WA, USA):

a. Date of birth

b. Gender: male/female

c. Presence of IPD and its underlying diagnosis as far as documented in the case file

d. Existence of a psychiatric certificate and psychiatric diagnosis warranting DGA (from January 1, 2007, to December 31, 2014)

e. Date of DGA

f. OPG: yes/no

g. Restorative therapy under DGA, assigned to tooth numbers

h. Tooth numbers of teeth extracted under DGA

From date of birth and date of DGA, the patients' age at the time of DGA was calculated. 


\section{Data analysis}

Demographic data was analyzed descriptively. According to the data type, results were reported as mean \pm standard deviation or absolute (relative) frequencies. For the comparative analysis of data in subgroups, Shapiro-Wilk Test was used to test the normality of data distribution. In case of a normal data distribution, $t$ test and in case of a not normal data distribution, Mann-Whitney U test was applied. Pearson Chi-Square test was used to compare categorical data in subgroups. Significance level was set at $p=0.05$. Computational work was performed using SPSS software (SPSS Statistics Version 21, IBM, Armonk, NY, USA).

\section{Results}

\section{Number of cases}

Altogether 444 cases of scheduled DGA in 322 adults with special needs were recorded in the time span from 2003 to 2014. Out of these, 402 cases $(90.5 \%)$ were attributed to 283 adults with IPD and 42 cases $(9.5 \%)$ were assigned to 39 adults diagnosed with PDs. Per year, 34 cases of patients with IPD and 5 cases of patients with PDs received scheduled DGA (within the time span 2003 to 2014 or 2007 to 2014, respectively). The difference in numbers per year between the two subgroups was statistically significant $(p<0.037$; Pearson Chi-Square test).

\section{Diagnoses}

\section{Patients with IPD}

In most of the 283 individuals with disablement, mental, and physical deficiencies were combined and referred to as "mental retardation" not further specified, or "autism," frequently in combination with "physical impairment," "epilepsy," "spasticity," or "hydrocephalus." Toxic or contagious embryopathy, perinatal hypoxia, developmental disorders (such as microcephalus), traumatic events, apoplectic (ischemic or hemorrhagic) insults, infectious diseases (such as meningoencephalitis), Alzheimer's disease, multiple sclerosis, and other harms were itemized as causes for brain damage. Further, inheritable diseases, such as Down's syndrome, Tourette's syndrome, Huntington's chorea, and other chromosomal abnormalities implicating various syndromic diseases were identified as medical conditions necessitating DGA.

\section{Patients with PDs}

A total of 39 individuals presenting with a psychiatric certificate were diagnosed with the following disorders: dentist phobia (15); other phobic behavior disorders (seven); depression (six), schizophrenia (four); emotional disorders (four); aggressive behavior disorders (two); and somatoform (eating) disorder (one).

\section{Multiple DGA}

Of all individuals treated under GA $(n=322), 61$ patients received DGA twice, 19 patients three times, five patients four times, and two patients five times within the observed period. In the group of individuals with IPD $(n=283), 58$ patients underwent DGA twice, 19 patients three times, five patients four times, and two patients five times. Three out of $39 \mathrm{pa}-$ tients with PDs had DGA twice.

\section{Age, gender, and OPG}

The distribution of age, gender, and availability of a preoperative OPG in patients with IPD and PDs is depicted in Table 1. Differences in age and gender between the two subgroups were not statistically significant, whereas the difference in the availability of a preoperative OPG was statistically highly significant ( $p<0.001$; Pearson Chi Square test).

\section{Restorative therapy and tooth extractions under DGA}

In a total of 444 cases, 2481 teeth were restored and 1279 teeth (1246 permanent and 33 primary teeth) were extracted. Per case, $5.59 \pm 4.58$ teeth (range 0 to 23 ) received restorative therapy and $2.81 \pm 4.06$ permanent teeth (range 0 to 28 ) were extracted.

Table 2 displays the means of restored and extracted teeth in patients with IPD and PDs.

Numbers of teeth restored/extracted differed significantly $(p=0.002) /$ highly significantly $(p<0.001)$ (Mann-Whitney $U$ test) between the two subgroups.

Out of 4381 surfaces restored in 2481 teeth, 1403 were occlusal, 926 were buccal, 858 were mesial, 774 were distal, and 420 were lingual. The total of 1246 extracted permanent teeth comprised $158(12.7 \%)$ maxillary incisors, $64(5.1 \%)$ maxillary canines, 211 (16.95\%) maxillary premolars, 269 (21.6\%) maxillary upper molars, 102 (8.2\%) mandibular incisors, $45(3.6 \%)$ mandibular canines, 150 (12\%) mandibular premolars, and 247 (19.85\%) mandibular molars.

Distribution of restored and extracted teeth per case (up to five teeth; six to ten teeth; 11 to 15 teeth; more than 15 teeth), see Tables 3 and 4.

\section{Discussion}

In the study collective, by numbers of patients, the demand for DGA was significantly higher in adults with IPD than in adults 
Table 1 Age, gender, and number of available orthopantomograms in patients with intellectual and/or physical disablement and in patients with psychiatric disorders

\begin{tabular}{|c|c|c|c|c|}
\hline & & $\begin{array}{l}\text { Cases in total } \\
n=444\end{array}$ & $\begin{array}{l}\text { Patients with } \\
\text { disablement } \\
\text { (cases) } n=402\end{array}$ & $\begin{array}{l}\text { Patients with psychiatric } \\
\text { disorders (cases) } n=42\end{array}$ \\
\hline Mean age & & $37.37 \pm 13.78$ & $37.5 \pm 13.87^{\mathrm{a}}$ & $36.09 \pm 13.03^{\mathrm{a}}$ \\
\hline \multirow[t]{2}{*}{ Gender } & Male & $245(55.2 \%)$ & $226(56.2 \%)^{\mathrm{b}}$ & $19(45.2 \%)^{\mathrm{b}}$ \\
\hline & Female & $199(44.8 \%)$ & $176(43.8 \%)^{\mathrm{b}}$ & $23(54.8 \%)^{\mathrm{b}}$ \\
\hline OPG & & 164 & $126(31.3 \%)^{\mathrm{c}}$ & $38(90.5 \%)^{\mathrm{c}}$ \\
\hline
\end{tabular}

$O P G$, orthopantomogram

${ }^{\mathrm{a}} p=0.55$; Mann-Whitney $U$ test

${ }^{\mathrm{b}} p=0.17$; Pearson Chi-Square test

${ }^{\mathrm{c}} p<0.001$; Pearson Chi-Square test

with PDs with inherent anxiety or (dentist) phobia. Per year, around 34 adults with IPD and five adults with PDs underwent scheduled DGA. This distribution may be partly explained by a reduced or non-existing approachability of patients with severe disablement by alternative methods and also by complex medical conditions frequently present in this group of special needs patients, which might lead to referral to a specialized hospital. In patients with PDs, the obligation to provide a psychiatric certificate attesting their inaptitude to receive dental treatment without GA might present a certain impediment for claiming DGA. Also, in patients suffering dental phobia, ongoing procrastination of dental consultations may in some cases culminate in acute painful conditions demanding immediate action rather than scheduled treatment [10, 11, 22-24].

Procrastination of dental consultation may also be an explanation for the fact that in this study, patients with PDs required significantly more restorations (in $7.98 \pm 5.4$ versus $5.34 \pm 4.41$ teeth) and extractions (of $4.86 \pm 4.51$ versus $2.6 \pm 3.96$ teeth) than patients with IPD, whose caretakers are usually obliged to arrange dental appointments. Altogether, at a mean age of around 36 to 37 years, there was a high demand for dental treatment in both groups. Thereby, restorative procedures outweighed tooth extractions. Other retrospective studies in special needs patients treated under DGA conformingly found a higher demand for restorative procedures than for extraction therapy in adolescents and adults $[25,26]$, whereas a recent 2-year retrospective review assessed a higher frequency of tooth extractions than restorations in special needs patients aged 16 to over 75 years [27]. The extractions-to-restorations ratio may (aside from the extent of carious decay or periodontal disease) depend on the applied treatment criteria, e. g., preventive measures such as pulp therapy/root canal treatment versus tooth extraction). Although single-visit endodontic treatment under general anesthesia has been considered a feasible treatment option [28], root canal treatment was not performed in the collective surveyed in the present study. According to internal directives, the risk of complications of endodontic treatment such as pain, swelling, fistula, radiologic failure, and consecutive tooth extraction [29] was not taken, in order to prevent clinical conditions necessitating further DGA. Both, the immanent risk of anesthetic complications of DGA in patients with special needs [15-17] and the hospital's limited capacity for (repeated) DGA supported the decision in favor of extraction of profoundly carious teeth (versus endodontic treatment) under DGA in this special clientele.

The difference in availability of preoperative OPGs between IPD and PDs patients is explainable by the intellectual and/or physical inability of persons with disablement to keep a steady head position for the required time, while most patients with dental phobia or other PDs seem to tolerate the taking of an OPG.

A survey in the general population of Austria in the year 2010 assessed a high level of oral health in 35- to 44-yearolds. Fifty one percent of this age group presented a complete natural dentition, 97\% reported daily oral hygiene, and $85 \%$ reported a dental consultation within the last 12 months [30]. In patients with IPD, in contrast, domestic oral care is challenging and sometimes even impossible. Additionally, some

Table 2 Restored and extracted teeth under DGA in patients with intellectual and/or physical disablement and in patients with psychiatric disorders

\begin{tabular}{lc}
\hline & $\begin{array}{l}\text { Patients with disablement } \\
\text { (Cases) } n=402\end{array}$ \\
\hline $\begin{array}{l}\text { Restored teeth under DGA per patient mean } \pm \mathrm{SD} \\
\text { disorders (Cases) } n=42\end{array}$ & $\begin{array}{c}5.34 \pm 4.41^{\mathrm{a}} \\
2.6 \pm 3.96^{\mathrm{b}}\end{array}$ \\
\hline
\end{tabular}

${ }^{\mathrm{a}} p=0.002$; Mann-Whitney $U$ test

${ }^{\mathrm{b}} p=0.002$; Mann-Whitney $U$ test 
Table 3 Number of teeth restored under DGA, assigned to cases

\begin{tabular}{ll}
$\begin{array}{l}\text { Number of } \\
\text { restored teeth }\end{array}$ & $\begin{array}{l}\text { Number of cases } \\
(n=444)\end{array}$ \\
\hline $0-5$ & $246(55.4 \%)$ \\
$6-10$ & $133(30 \%)$ \\
$11-15$ & $48(10.8 \%)$ \\
$>15$ & $17(3.8 \%)$ \\
\hline
\end{tabular}

medications such as antiepileptics (causing gingival hyperplasia) or antidepressants (causing mouth dryness) may further worsen the oral condition. All the same, in case of noncooperation or defense, routine dental examination and/or treatment is doomed to fail. In these cases, DGA provides improved conditions for clinical assessment and treatment, although the increased risk of anesthetic complications in special needs patients frequently displaying complex medical disorders must be considered [31]. At the University Hospital of Innsbruck, after a thorough preoperative examination with respect to suitability for GA and, if required, an appropriate premedication, DGA is performed by a dental consultant, if necessary with the help of an oral surgeon, in cooperation with an experienced anesthetist by use of the armamentarium, facilities and staff available in a hospital center. No severe perior postoperative complications were reported in the study sample. However, DGA in patients with severe disablement seems a Sisyphean task (in terms of necessity of repeated DGA) if an improvement in daily oral care is not contrivable. In patients with minor disablement or in patients suffering anxiety or phobia, oral hygiene instructions and periodic professional cleaning may well be of avail. An empathetic approach (maybe along with alternative methods, such as behavior management, hypnodontia, conscious sedation, or nitrous oxide analgesia, or along with concomitant psychiatric or psychological counseling) may facilitate dental treatment without general anesthesia. Alas, in Austria, the costs for alternative methods are — unlike for DGA in a public hospital— not met by the public health fund. Regular dental checkups after DGA have been shown to affect a reduced demand for further invasive treatments [32]. So far, in Innsbruck, a systematical recall program has not been implemented but should be considered for the future. At the Hospital of Dental Prosthetics and

Table 4 Number of teeth extracted under DGA, assigned to cases

\begin{tabular}{lc}
\hline $\begin{array}{l}\text { Number of } \\
\text { extracted teeth }\end{array}$ & $\begin{array}{l}\text { Number of cases } \\
(n=444)\end{array}$ \\
\hline $0-5$ & $379(85.4 \%)$ \\
$6-10$ & $42(9.4 \%)$ \\
$11-15$ & $12(2.7 \%)$ \\
$>15$ & $11(2.5 \%)$ \\
\hline
\end{tabular}

Restorative Dentistry, once a week, patients with (minor) IPD, attended by the nonprofit association "Lebenshilfe (Counseling) Tirol," receive scheduled professional oral hygiene and/or, when possible, dental treatment (under local anesthesia), including (mostly removable) prosthetic rehabilitation. The management of special needs patients presents a challenging and time-consuming task and requires accessible facilities [33] as well as a dedicated staff. In severe cases of disablement, DGA remains the only treatment option.

This study provides relevant data on the oral health status of special needs patients treated under DGA. Limitations of this study are owed to its retrospective character. Further data of interest, such as previously filled and missing teeth, the type of residence or care (home or institutional), and the mode and extent of aftercare following DGA were not (consistently) available from patient files.

\section{Clinical relevance}

By numbers of patients, in investigated collective, demand for DGA was significantly higher in adults with IPD than in adults with PDs associated with anxiety or phobia. While in patients with severe disablement DGA seems to present the only treatment option, specific preventive dental programs (carried out by specialized teams in centers or dental practices) should be implemented for the management of patients with minor disablement or patients suffering psychiatric disorders $[10,34$, 35]. In these patients, the promotion of alternative approaches such as behavior management, hypnodontia, or conscious sedation should be considered.

Funding Open access funding provided by University of Innsbruck and Medical University of Innsbruck. The work was supported by the University Hospital of Dental Prosthetics and Restorative Dentistry of the Medical University of Innsbruck, Austria.

\section{Compliance with ethical standards}

Conflict of interest The authors declare that they have no conflict of interest.

Ethical approval The present study was carried out in accordance with the 1964 Declaration of Helsinki and its later amendments, and ethical approval was obtained by the institutional ethical committee, study number AN2014-0269 341/4.8 (3621a).

Informed consent For this type of study (retrospective analysis of anonymized data), formal consent is not required.

Open Access This article is distributed under the terms of the Creative Commons Attribution 4.0 International License (http:// creativecommons.org/licenses/by/4.0/), which permits unrestricted use, distribution, and reproduction in any medium, provided you give appropriate credit to the original author(s) and the source, provide a link to the Creative Commons license, and indicate if changes were made. 
Publisher's note Springer Nature remains neutral with regard to jurisdictional claims in published maps and institutional affiliations.

\section{References}

1. Mallineni SK, Yiu CK (2016) Dental treatment under general anesthesia for special-needs patients: analysis of the literature. J Investig Clin Dent 7:325-331. https://doi.org/10.1111/jicd.12174

2. Vargas-Román MP, Rodríguez-Bermudo S, Machuca-Portillo G (2003) Dental treatment under general anesthesia: a useful procedure in the third millennium? (1). Med Oral 8:129-135

3. WHO (1980) International classification of impairments, disabilities, and handicaps. https://whqlibdoc.who.int/publications/1980/ 9241541261_eng.pdf. Accessed 3 Feb 2019

4. Royal Australasian College of Dental Surgeons (2017) Specialist Dental Practice 2014. https://www.racds.org/RACDSNEW Content/Education/Specialist_Dental_Practice.aspx. Accessed 4 April 2017

5. Nunn JH, Davidson G, Gordon PH, Storrs J (1995) A retrospective review of a service to provide comprehensive dental care under general anesthesia. Spec Care Dentist 15:97-101

6. Pregliasco F, Ottolina P, Mensi C, Carmagnola D, Giussani F, Abati S, Strohmenger L (2001) Oral health profile in an institutionalized population of Italian adults with mental retardation. Spec Care Dentist 21:227-231

7. Schulte AG, Freyer K, Bissar A (2013) Caries experience and treatment need in adults with intellectual disabilities in two German regions. Community Dent Health 30:39-44

8. da Silva SN, Gimenez T, Souza RC, Mello-Moura ACV, Raggio DP, Morimoto S, Lara JS, Soares GC, Tedesco TK (2017) Oral health status of children and young adults with autism spectrum disorders: systematic review and meta-analysis. Int J Paediatr Dent 27:388-398. https://doi.org/10.1111/ipd.12274

9. Morgan JP, Minihan PM, Stark PC, Finkelman MD, Yantsides KE, Park A, Nobles CJ, Tao W, Must A (2012) The oral health status of 4,732 adults with intellectual and developmental disabilities. J Am Dent Assoc 143:838-846

10. Angelillo IF, Nobile CG, Pavia M, De Fazio P, Puca M, Amati A (1995) Dental health and treatment needs in institutionalized psychiatric patients in Italy. Community Dent Oral Epidemiol 23:360-364

11. Waplington J, Morris J, Bradnock G (2000) The dental needs, demands and attitudes of a group of homeless people with mental health problems. Community Dent Health 17:134-137

12. Rashewsky S, Parameswaran A, Sloane C, Ferguson F, Epstein R (2012) Time and cost analysis: pediatric dental rehabilitation with general anesthesia in the office and the hospital settings. Anesth Prog 59:147-153. https://doi.org/10.2344/0003-3006-59.4.147

13. Manley MC, Skelly AM, Hamilton AG (2000) Dental treatment for people with challenging behaviour: general anaesthesia or sedation? Br Dent J 188:358-360

14. Dougherty N (2009) The dental patient with special needs: a review of indications for treatment under general anesthesia. Spec Care Dentist 29:17-20. https://doi.org/10.1111/j.1754-4505.2008.00057.x

15. Messieha Z (2009) Risks of general anesthesia for the special needs dental patient. Spec Care Dentist 29:21-25. https://doi.org/10.1111/ j.1754-4505.2008.00058.x.

16. Shin TJ, Noh GJ, Koo YS, Han DW (2014) Modeling of recovery profiles in mentally disabled and intact patients after sevoflurane anesthesia; a pharmacodynamic analysis. Yonsei Med J 55:16241630. https://doi.org/10.3349/ymj.2014.55.6.1624

17. Higuchi H, Maeda S, Ishii-Maruhama M, Honda-Wakasugi Y, YabukiKawase A, Miyawaki T (2017) Intellectual disability is a risk factor for delayed emergence from total intravenous anaesthesia. J Intellect Disabil Res 62:217-224. https://doi.org/10.1111/jir.12448
18. Goodwin M, Sanders C, Davies G, Walsh T, Pretty IA (2015) Issues arising following a referral and subsequent wait for extraction under general anaesthetic: impact on children. BMC Oral Health 17(15): 23. https://doi.org/10.1186/1472-6831-15-3

19. Gluhak C, Arnetzl GV, Kirmeier R, Jakse N, Arnetzl G (2010) Oral status among seniors in nine nursing homes in Styria, Austria. Gerodontology 27:47-52. https://doi.org/10.1111/j.1741-2358. 2009.00281.x

20. Steinmassl PA, Steinmassl O, Kraus G, Dumfahrt H, Grunert I (2016) Shortcomings of prosthodontic rehabilitation of patients living in long-term care facilities. J Oral Rehabil 43:286-290. https:// doi.org/10.1111/joor.12359

21. Steinmassl PA, Steinmassl O, Kraus G, Dumfahrt H, Grunert I (2016) Is cognitive status related to oral hygiene level and appropriate for determining need for oral hygiene assistance? J Periodontol 87:41-47. https://doi.org/10.1902/jop.2015.150349

22. ter Horst G (1992) Dental care in psychiatric hospitals in The Netherlands. Spec Care Dentist 12:63-66

23. Chalmers JM, Kingsford Smith D, Carter KD (1998) A multidisciplinary dental program for community-living adults with chronic mental illness. Spec Care Dentist 18:194-201

24. McCreadie RG, Stevens H, Henderson J, Hall D, McCaul R, Filik R, Young G, Sutch G, Kanagaratnam G, Perrington S, McKendrick J, Stephenson D, Burns T (2004) The dental health of people with schizophrenia. Acta Psychiatr Scand 110:306-310

25. Mallineni SK, Yiu CKY (2018) A retrospective audit of dental treatment provided to special needs patients under general anesthesia during a ten-year period. J Clin Pediatr Dent 42:155-160. https://doi.org/10.17796/1053-4628-42.2.13

26. Savanheimo N, Sundberg SA, Virtanen JI, Vehkalahti MM (2012) Dental care and treatments provided under general anaesthesia in the Helsinki Public Dental Service. BMC Oral Health 12:45. https:// doi.org/10.1186/1472-6831-12-45

27. Ali S, Sims C, Foy S, McIndoe A, Yates R, Brooke T (2016) A review of daycase GA services for Special Care patients at University Hospital, Bristol. Community Dent Health 33:6-8. https://doi.org/10.1922/CDH_3708Ali03

28. Chang J, Kim HY (2017) Prognostic factors of single-visit endodontic and restorative treatment under general anaesthesia for special needs patients. J Oral Rehabil 44:96-104. https://doi.org/10. 1111 joor. 12458

29. Manfredi M, Figni L, Gagliani M, Lodi G (2016) Single versus multiple visits for endodontic treatment of permanent teeth. Cochrane Database Syst Rev 12:CD005296. https://doi.org/10. 1002/14651858.CD005296.pub3

30. Bodenwinkler A, Kerschbaum J, Sax G (2011) Mundgesundheit und Lebensqualität in Österreich 2010. Österreichisches Bundesinstitut für Gesundheitswesen (ed) Vienna. https:// repository.publisso.de/resource/frl:4661714-1/data. Accessed 29 Oct 2018

31. Weaver JM (1995) Special considerations concerning general anesthesia for dental treatment of handicapped patients. Anesth Prog 42: 93-94

32. Oh TJ, Nam OH, Kim MS, Choi SC, Lee HS (2018) Oral health of patients with special health care needs after general anesthesia: a 25year retrospective study. Pediatr Dent 40:215-219

33. Baird WO, McGrother C, Abrams KR, Dugmore C, Jackson RJ (2008) Access to dental services for people with a physical disability: a survey of general dental practitioners in Leicestershire, UK. Community Dent Health 25:248-252

34. Hede B (1995) Dental health behavior and self-reported dental health problems among hospitalized psychiatric patients in Denmark. Acta Odontol Scand 53:35-40

35. Lewis S, Jagger RG, Treasure E (2001) The oral health of psychiatric in-patients in South Wales. Spec Care Dentist 21:182-186 